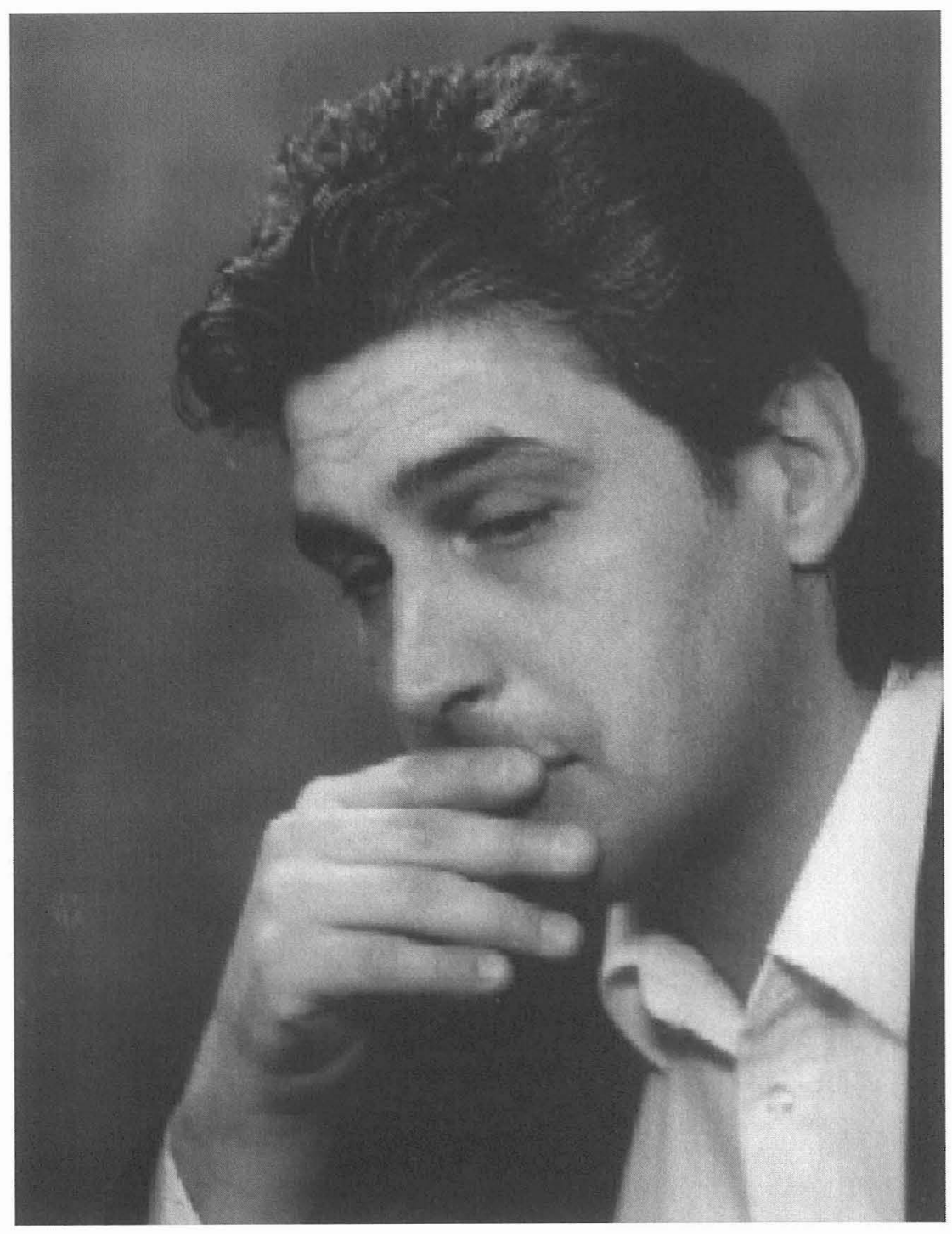

RENAUd LONGCHAMPS 
Renaud Longchamps est né en 1952 à Saint-Ephrem-de-Beauce où il vit toujours. Il a publié de nombreux recueils de poèmes et une trilogie romanesque intitulée Babelle. Sa poésie est traduite en plusieurs langues, dont l'anglais, l'espagnol et l'italien. En 1988, il reçoit le Prix Émile-Nelligan pour Légendes suivi de Sommation sur l'histoire et en 1992, le Grand Prix du Festival international de la poésie pour Décimations : la fin des mammiferes. Au printemps 1999, les Éditions Trois-Pistoles ont entrepris la publication de l'œuvre complète qui comporte plus de trente ouvrages: Euvres complètes. Tome 1, Passions, 1999; Tome 2, Explorations, 1999; Tome 3, Evolutions: 2000; Tome 4, Générations, 2001; Supplément au Tome 1, Passions retrouvées, 2001.

\section{CONFESSIONS NÉGATIVES}

\section{PREMIÈRE CONFESSION}

J

e n'aime pas cette vie

J'aime la vie

Celle qu'on m'a donnée n'a pas été inventée mais bricolée à l'ombre de la mort

Je n’y peux rien

Je suis le descendant d'une longue lignée de malentendus avec pour seule femme

la parole innée à l'horizon

Ainsi j'ai perdu l'habitude des certitudes

Hier j’ai vu un insecte briller sous le soleil du dévonien avant de s'envoler dans le vieux ciel titane sans jamais s'arrêter sur l'air qui le porte jusqu'au ciel 
Aujourd'hui

je suis un insecte

déchu de ses ailes

et je sais tout de l'air

J'ai évolué

certes

mais on ne m'a rien donné

pour combattre l'énorme erreur gravée

dans mes gènes lilliputiens

On ne m'a rien donné pour m'envoler loin de la peur aveugle qui ravage

la mémoire de mes amours et de mes haines

J'ai évolué

certes

quitte à me répéter

dans mes mots comme dans mes morts

mais je suis sans cesse dérangé

avec ou sans ailes

dans mon rêve d'éternité qui va nulle part

Vous savez

j’ai été heureux

car j'ai pratiqué toutes les bouches

C'est pourquoi le mot me donne la vie

C'est pourquoi on me l'enlève tous les matins

quand je m'éveille

quand j'entends mon corps se disloquer

avant mon cœur 
Ne craignez rien

Je sais où je serai

dans cent ans

Ne craignez rien

Je ne serai pas mort

Je vivrai dans le corps défait

d'un autre

qui marchera aussi sans but et sans silence

avec mes mots

dans sa bouche toujours crue

Il fredonnera :

"Les jeux sont faits

pour la beauté des hasards »

« Les yeux sont faits

pour être défaits

par la laideur "

Puis je quitterai encore une fois

un corps en friche

Je n'y peux rien

La nature avance toujours sur la vie

Mais je sais où je serai

dans mille ans

$\mathrm{Ne}$ craignez rien

Je ne serai plus mort 
Je vivrai dans le corps d'un autre en marche vers le néant

Dans un corps qui n'a rien à comprendre à mes mots qui n'a rien à prendre sur la mort

Dans ce corps

je ne serai plus vivant

de la vie de tous les autres

Je serai la beauté

qui tracera pour l'éternité

la frontière de la vie 